\title{
Phytotoxicity of "Tide" Detergent Powder Using Lens culinaris Seeds as a Bioassay
}

\author{
Xiang Cai ${ }^{1,2 *}$ and Sergei A Ostroumov ${ }^{1,2}$ \\ ${ }^{1}$ Faculty of Biology, Lomonosov Moscow State University, Moscow, Russian \\ Federation \\ ${ }^{2}$ Department of Ecology, School of Biology, Shenzhen MSU-BIT University, \\ Shenzhen, China \\ *Corresponding Author: Xiang Cai, Faculty of Biology, Lomonosov Moscow State \\ University, Moscow, Russian Federation
}

Received: December 29, 2021

Published: January 10, 2022

(C) All rights are reserved by Xiang Cai and Sergei A Ostroumov

\begin{abstract}
The indiscriminate use of synthetic laundry detergents (SLDs) triggered notorious prevalence of toxic pollution in water environment. SLDs synthesized from surfactants and other chemical compounds pose ecotoxic risk to living organisms once invading the ecosystem. The widespread presence of terrestrial vegetations in ecosystem may be subject to exposure to SLDs. It is important to test phytotoxic effect of SLDs on terrestrial plant species and form a system of phytotoxic risk assessment. The phytotoxicity of "Tide" detergent powder (TDP) was tested using Lens culinaris seeds as a bioassay. The bioassay showed that the seed germination percentage (ca. $0 \%$ - 90\%) reduced sharply due to an increase in TDP concentrations (0.0\%, 0.1\%, 0.5\% and 1.0\%) within 72-h and 96-h, respectively. Meanwhile, the increasing concentrations inhibited root elongation (ca. 0.0 - $8 \mathrm{~mm}$ ) after 72-h long exposure to TDP, and also impeded root elongation (ca. 0.0 - $17 \mathrm{~mm}$ ) after 96-h. The phytotoxicity was assessed depended on two indices: seed germination and root elongation indices. The present study validated an effective and economical bioassay, in which the phytotoxicity ranks (slight, moderate, high and extreme) were graded.
\end{abstract}

Keywords: Phytotoxicity; Lens culinaris; “Tide” Detergent Powder; Seed Germination; Root Elongation

\section{Abbreviations}

SLDs: Synthetic Laundry Detergents; TDP: “Tide” Detergent Powder; EC: Effective Concentration; ET: Exposure Time; SG: Seed Germination; RE: Root Elongation; GP: Germination Percentage; RL: Root Length; SGI: Seed Germination Index; REI: Root Elongation Index

\section{Introduction}

Urbanization expanding and economic soaring caused a growing trend towards overuse and pollution of SLDs for household, commercial and industrial cleanup due to rampant anthropogenic activities [1,2]. As far as the quantity of SLDs was discharged, millions of tons per year was depleted and dumped in untreated forms or in treated effluents from wastewater treatment plants to the destinated water areas like river watersheds, estuaries and coastal seawaters, etc. [3-5]. The misuse of SLDs could challenge environmental conservation and public health. It should be noted that not just can the SLDs itself pollute water resources, but may the treated effluents also retain the surfactants (e.g., linear alkylbenzene sulphonate, alky phenol ethoxylate, etc.) and persist in the water environment $[1,6]$.

It is well documented that surfactant is the principal constituent of SLDs $[1,4]$. The chemical amphiphilicity of surfactant molecules determine that the SLDs can emulsify the organic contaminants in water by dissolving organic varieties (both soluble and insoluble organics) and suspending them for a long-term [7,8]. This may result in the persistent detergent contamination in aquatic ecosystem. On the other side, the hydrophobic affinity enable the SLDs to 
be adsorbed by the sludge and sediments [1,8]. Agricultural application of the SLDs-rich sludge to soil amendment and the SLD-contained effluents for agricultural irrigation could expand detergent contamination from aquatic ecosystem to terrestrial agroecosystem [9].

The notorious prevalence of SLDs contamination in both aquatic and terrestrial ecosystems grows worldwide concern over the toxicity to living organisms. In general, the SLDs is formulated by surfactants, builders, bleachers, enzymes, and fragrant agents, etc. $[1,2,4,5,10]$. However, most of them pose adverse effects on plants animals and microorganisms [10-13]. Surfactants may carry xenobiotics to jeopardize the aquatic organisms, decrease the dissolved oxygen supply, and block sunlight via the formation of white foams on water surface $[5,7]$. Moreover, the toxic by-products (e.g., nonyl and octyl phenols, etc.) of surfactants due to biodegradation are considered as estrogen-like compounds and suspected carcinogens [14]. The elementary compositions of builders are phosphates, which are responsible for algal blooming and then eutrophication $[7,10]$. Bleaches present carcinogenicity and mutagenicity since they contain optical brighteners and fluorescent whitening agents $[2,15]$. The other additives in SLDs such as enzymes and fragrant agents may act as a trigger for endocrine disruptions and fragrance allergens, respectively [16,17]. As a synthetic admixture formulated by such many potentially toxic compounds, however, the toxicity of SLDs still remains intangible. Though the toxicity of SLDs was studied and reported, the ecotoxicological researches have paid limited attention to the phytotoxicity using higher terrestrial plant species as a bioassay.

In retrospective, a number of bioassays using lettuce (Lactuca sativa L.), rice (MR 220), aquatic macrophytes and lentil (Lens culinaris), etc. had been reported $[9,10,18,19]$. Furthermore, The United States Environmental Protection Agency (USEPA) worked out the national guideline (OPPTS 850.4200) to normalize the SG/ RE toxicity bioassay using the test model plants, such as tomato (Lycopersicon esculentum), cucumber (Cucumis sativa), oat (Avena sativa), etc. [20]. In this present study, Lens culinaris was employed to test for the toxicity of TDP that was the worldwide bestseller characteristic of SLDs [10,21-24]. The data of the SG and RE tests were converted as the results (mean value \pm standard error) of GP and RL, respectively. The GP results were conduct to calculate SGI, while the RL ones were for REI. Depended on the two overarching indices, the ranks (slight, moderate, high and extreme toxicity) of phytotoxic risk were assessed in the bioassay. Eventually, a simple but sensitive, effective and economical bioassay was concluded.

\section{Materials and Methods}

Test chemicals and plant material

The TDP was purchased from Procter and GSMP distribution franchiser (Guangzhou, China). The formulation analysis indicates that the TDP generally comprises anionic surfactant (5\%-15\%), nonionic surfactant $(5 \%)$, enzyme $(<1 \%)$, and fragrant agents $(<1 \%)$, etc. Lens culinaris seeds (usually one year aged) were obtained from Ailimeng Seed Sci-Tech Co., Ltd (Shanghai, China). The handpicked seeds (mean seed size: $7.0 \pm 0.5 \mathrm{~mm}$ ) were qualified as model testers, in accordance with the criteria of phytotoxicity tests $[23,24]$. The remainder of seeds then were packed in a plastic bag and maintained at $4^{\circ} \mathrm{C}$ in a refrigerator.

\section{Preparations of the test solutions and bioassay}

Deionized water supplied by the Lab Water Purifier (Shang Canrex Analytic Instrument, Shanghai, China) was used as aqueous medium for preparing all test solutions. To prepare the stock solution $(5.0 \%, \mathrm{w} / \mathrm{w})$, it weighed $25.00 \mathrm{~g}$ of TDP and dissolved in 500 $\mathrm{mL}$ of deionized water using a volumetric flask (BOMEX, $500 \mathrm{~mL}$, $\left.20{ }^{\circ} \mathrm{C}\right)$. A series of test solutions $(0.1 \%, 0.5 \%$ and $1.0 \%)$ were prepared by diluting the TDP stock solution at appropriate ratios using another type of volumetric flask (BOMEX, $100 \mathrm{~mL}, 20{ }^{\circ} \mathrm{C}$ ). The remainder of stock solution was refrigerated at $4{ }^{\circ} \mathrm{C}$ for next use.

A method of hydroponic culture is introduced to the static bioassay for the phytotoxic risk assessment [18,19,23]. The hydroculture was conducted in the vitreous petri dishes (diameter: 100 $\mathrm{mm}$, height: $15 \mathrm{~mm}$ ) lined with qualitative filter papers (diameter: $110 \mathrm{~mm}$ ), where Lens culinaris seeds were sown in direct exposure to the test detergent. All prepared samples were placed and incubated in an artificial climate chamber (Ningbo Southeast Instrument, Ningbo, China) for 72 -h or $96-\mathrm{h}$, in the dark ambience at a controlled temperature $\left(25.0 \pm 1.5^{\circ} \mathrm{C}\right)$. Seeds in the bioassay were handpicked out from raw crop products. These select seeds were sterilized using hydroperoxide (ca. $5 \% \mathrm{H}_{2} \mathrm{O}_{2}$ ) for $5 \mathrm{~min}$, and rinsed 5-10 times with deionized water to eliminate the sterilizer from the seed testa surface $[24,25]$. Afterwards, the samples were triplicated in a control and the three tests at three different ECs. Accordingly, a total of 360 sterilized seeds were sown in 12 dishes evenly, 
in which each dish contained 30 seeds and triplicate dishes in a ternary must have 90 seeds. The well-sown seeds per dish were moistened with addition $(20 \mathrm{~mL})$ of the test solution and labelled as test $0.1 \%$, test $0.5 \%$ and test $1.0 \%$, respectively. Deionized water $(20 \mathrm{~mL})$ was added into control (test $0.0 \%$ ) in comparison to the tests. According to hydroculture bioassay guideline, seed germination is determined by the root length longer than $2 \mathrm{~mm}[24,25]$.

\section{Mathematical processing}

The data of bioassay were processed using some mathematical formulas, in a bid for quantitative assessment of phytotoxicity. The GP was calculated via equation (1) to represent the testing results of the SG endpoint [26]. The measurements of RE were recorded as values of RL using a digital vernier caliper (DL91150, Ningbo, China).

$$
\begin{aligned}
& \mathrm{GP}=\frac{\sum_{\mathrm{i}}^{3} \mathrm{G}(\mathrm{i})}{90} \times 100 \% \\
& \mathrm{SGI}=\frac{\mathrm{G}_{\mathrm{t}}-\mathrm{G}_{\mathrm{C}}}{\mathrm{G}_{\mathrm{c}}} \\
& \mathrm{REI}=\frac{\overline{\mathrm{L}_{\mathrm{t}}}-\overline{\mathrm{L}_{\mathrm{C}}}}{\overline{\mathrm{L}_{\mathrm{C}}}}
\end{aligned}
$$

Where G(i): number of germinated seeds per petri dish in control/tests; $G_{t}$ : number of germinated seeds per ternary in tests, $G_{c}$ : number of germinated seeds per ternary in control, : mean RL per ternary in tests, : mean RL per ternary in control. According to the obtained empirical values ranging from -1 to 0 , the toxicity can be ranked into four levels such as (1) slight $(-0.25 \leq$ SGI or REI $<0)$, (2) moderate $(-0.5 \leq \mathrm{SGI}$ or REI $<-0.25)$, (3) high $(-0.75 \leq \mathrm{SGI}$ or REI $<-0.5)$, and (4) extreme toxicity $(-1 \leq$ SGI or REI $<-0.75)[18,24]$.

The SGI was developed to assess the acute phytotoxicity (equation (2)), while equation (3) provided a way to parameterize the REI for risk assessment of the chronic phytotoxicity [26].

\section{Data treatment}

The data points were treated using $t$-test and non-parametric Kruskal-Wallis test offered by Excel 2019 program. The data that patterned normal distribution were analyzed using $t$-test, while non-parametric model used to treat those data that exhibited non-normal distribution. Finally, the two-way analysis of variance (ANOVA) validated the significant differences $(p<0.05)$ between tests and control in the bioassays. The error bars in the study were subject to standard errors.

\section{Results and Discussion}

Image analysis

The most representative images of the samples in the tests (i.e., the test $0.1 \%, 0.5 \%$ and $1.0 \%$ ) and in control $(0.0 \%)$ were presented in figure 1. From the illustrated images, it is quite pronounced to see that the number of germinated seed decreased with the increase in concentration after 72-h hydroponic incubation. The maximum germinated number (23 seeds) was found in control (Figure 1 (a)). It noted that deionized water (0.0\%) appeared harmless to Lens culinaris SG. By stark contrast, no germinated seed was found, as observed the samples in the test $1.0 \%$ (Figure 1 (d)). It was concerned that $1.0 \%$ was a lethal EC of TDP in the bioassay. In addition, $0.1 \%$ and $0.5 \%$ were the characteristics of the sublethal concentrations to inflict a low-toxic adverse effect on the seeds. As shown in figure 1 (b), 17 of germinated seeds were found in the test $0.1 \%$, while only a seed germinated in the test $0.5 \%$ was observed (Figure 1 (c)).

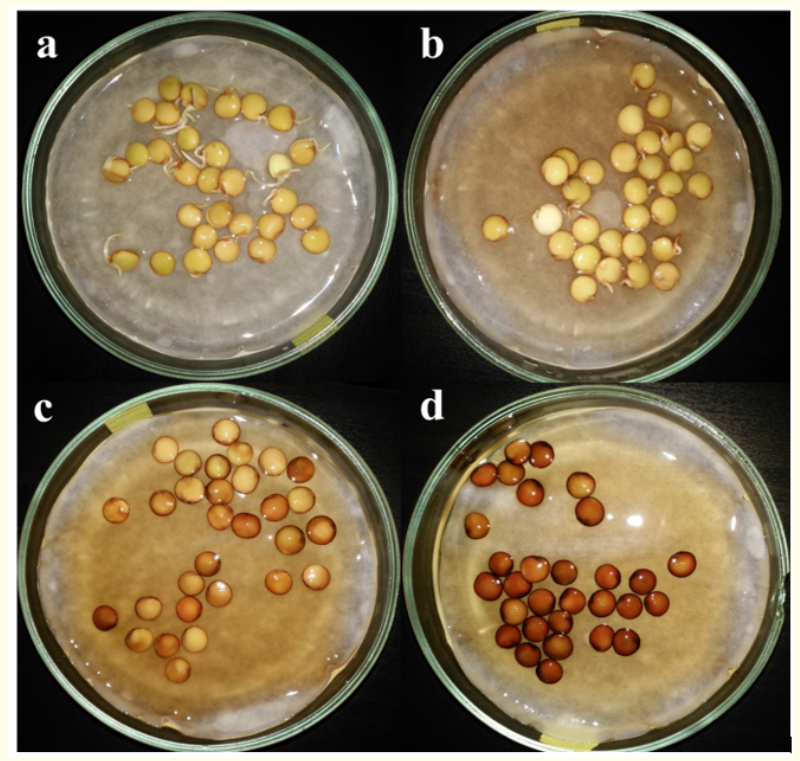

Figure 1: The morphological characteristics of Lens culinaris seeds imaged after 72-h long exposure to TDP solution. The sowed seeds were moistened and immersed at the EC from $0.0 \%$ to $1.0 \%$ (i.e., $0.0 \%$ (control), $0.1 \%, 0.5 \%$ and $1.0 \%$ ).

\section{The SG tests}

The number of germinated seeds decreased after 72-h or 96-h long hydroponic incubation at an increasing EC (i.e., 0.0\% (control), $0.1 \%, 0.5 \%$ and $1.0 \%$ ) of the TDP solution. The GP of germi- 
nated versus total number of the seeds calculated via equation (1) in the form of mean \pm standard error shown in table 1 . It can be seen that GP decreased from $92 \%(\mathrm{p}<0.05)$ to $0.00 \%$ after 72 -h and 96 -h, respectively (Figure 2 ). In agreement with bioassay images (Figure 1), it reaffirmed the fact that the lower EC of TDP, the higher GP could be found.

\section{The RE tests}

Exposure to TDP at different ECs (i.e., $0.0 \%, 0.1 \%, 0.5 \%$ and $1.0 \%$ ) resulted in the variations of RL measured in the RE endpoint tests. In line with the SG results (Table 1), the mean value of RL also lessened due to the increase in EC (Table 2). In the control, the robust concentration $(0.0 \%)$ promoted the sustainable elongation of Lens culinaris roots from $8 \mathrm{~mm}(72-\mathrm{h})$ to $17 \mathrm{~mm}$ (96-h) in RL (Figure 3 ). In the test $0.1 \%$, the roots also sustained to elongate by $3 \mathrm{~mm}$ in RL from 72-h to 96 -h at the sublethal EC $(0.1 \%)$ (Figure $3)$. No RL could be measured in the test $0.5 \%$ and $1.0 \%$. It suggests that (1) the control validated the methodic viability of Lens culinaris bioassay; (2) Lens culinaris could survive at sublethal EC (chronic toxicity) of TDP; (3) Lens culinaris deceased at high and lethal EC (acute toxicity). Finally, a concentration-response relationship between the RE and the EC was proved.

\begin{tabular}{|l|c|c|c|c|c|c|c|}
\hline \multirow{2}{*}{ EC (\%) } & \multicolumn{3}{|c|}{ 72-h } & & \multicolumn{3}{c|}{ 96-h } \\
\cline { 2 - 8 } & GP (\%) & SGI & Risk Rank & & GP (\%) & SGI & Risk Rank \\
\hline 0.0 (control) & $88.89 \pm 2.27$ & 0.00 & - & & $88.89 \pm 2.27$ & 0.00 & - \\
\hline 0.1 & $69.44 \pm 8.18$ & -0.22 & Slight & & $80.56 \pm 6.00$ & -0.09 & Slight \\
\hline 0.5 & $2.78 \pm 2.27$ & -0.97 & Extreme & & $2.78 \pm 2.27$ & -0.97 & Extreme \\
\hline 1.0 & $0.00 \pm 0.00$ & -1.00 & Extreme & & $0.00 \pm 0.00$ & -1.00 & Extreme \\
\hline
\end{tabular}

Table 1: Phytotoxic effect of TDP on Lens culinaris SG. The GP represents the testing results of the SG endpoint in exposure to TDP solution at various ECs (i.e., .0\% (control), $0.1 \%, 0.5 \%$ and $1.0 \%$ ) after either 72 -h or 96 -h.

\begin{tabular}{|l|c|c|c|c|c|c|c|}
\hline \multirow{2}{*}{ EC (\%) } & \multicolumn{3}{|c|}{$\mathbf{7 2 ~ h}$} & \multicolumn{3}{c|}{$96 \mathbf{~ h}$} \\
\cline { 2 - 7 } & RL (mm) & REI & Risk Rank & RL (mm) & REI & Risk Rank \\
\hline 0.0 (control) & $8.24 \pm 0.81$ & 0.00 & - & $17.07 \pm 1.46$ & 0.00 & - \\
\hline 0.1 & $4.05 \pm 0.48$ & -0.51 & High & $7.34 \pm 0.85$ & -0.57 & High \\
\hline 0.5 & $0.12 \pm 0.10$ & -0.98 & Extreme & $0.13 \pm 0.10$ & -0.99 & Extreme \\
\hline 1.0 & $0.00 \pm 0.00$ & -1.00 & Extreme & $0.00 \pm 0.00$ & -1.00 & Extreme \\
\hline
\end{tabular}

Table 2: Phytotoxic effect of TDP on Lens culinaris RE. The RL represents the testing results of the RE endpoint in exposure to TDP solution at various ECs (i.e., .0\% (control), $0.1 \%, 0.5 \%$ and $1.0 \%$ ) after either 72 -h or 96 -h.

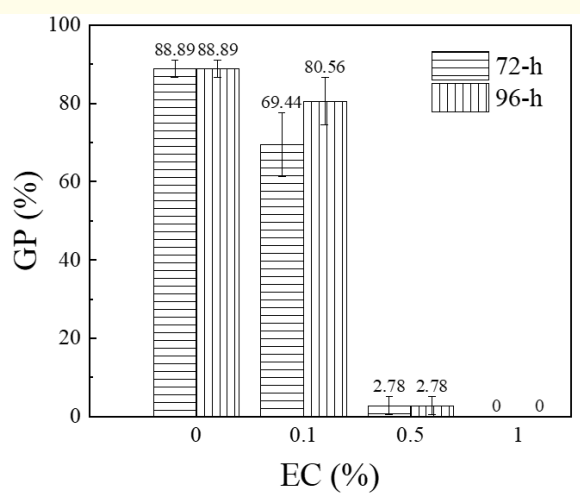

Figure 2: The adverse effect of TDP solution on Lens culinaris SG worsened as the EC increased. The GP (\%) of the SG number versus the total number varied depended on the ECs $(0.0 \%$ (control), $0.1 \%, 0.5 \%$ and $1.0 \%$ ) of TDP under the darkness at a controlled temperature of $20.0 \pm 1.5^{\circ} \mathrm{C}$, after 72 -h or 96 -h long hydroponic incubation, respectively.

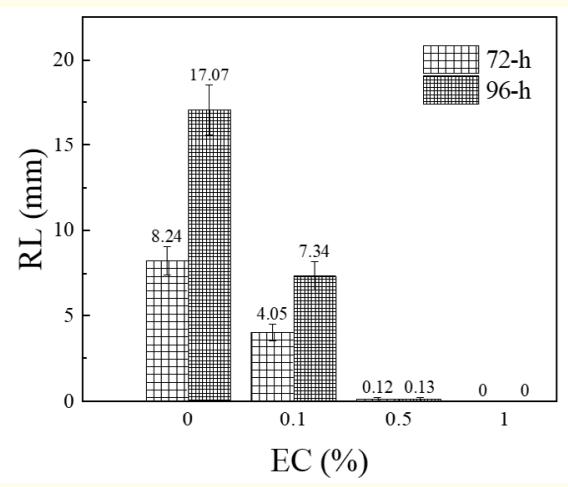

Figure 3: The adverse effect of TDP solution on Lens culinaris $\mathrm{RE}$ aggravated as the EC increased. The measurements of RL $(\mathrm{mm})$ as the results of RE varied according to the ECs $(0.0 \%$ (control), $0.1 \%, 0.5 \%$ and $1.0 \%$ ) of TDP under the darkness at a controlled temperature of $20.0 \pm 1.5^{\circ} \mathrm{C}$, after 72 -h or 96 -h long hydroponic incubation, respectively. 
Risk and potential assessment of phytotoxicity

Based on the results of SG (GP values) and RE (RL values) tests, the values of SGI and REI were worked out and presented in table 1 and 2 . The low EC $(0.1 \%)$ induced slight phytotoxicity Lens culinaris germination according to the SGI values $(-0.25<-0.22(72-\mathrm{h})$ or $-0.09(96-\mathrm{h})<0.00)$. When EC increased to high content (e.g., $0.5 \%$ and $1.0 \%)$, the SGI (-0.9 or -1.0$)$ assessed extreme phytotoxicity. Nonetheless, REI values $(-0.51(72 \mathrm{~h})$ or -0.57 (96 h) $<-0.5)$ showed that $0.1 \%$ EC of TDP could cause high phytotoxicity, compared to slight phytotoxicity ranked by using SGI. This confirmed that the REI was more restricted and sensitive phytotoxicity index than the SGI $[9,19,23]$.

\section{Conclusion}

The bioassay carried out the SG and RE tests for the phytotoxicity of TDP dissolved in aqueous solution at different concentrations. The measurements and calculations of the SG and RE endpoints are the GP and RL values. The sharp decrease in GP and RL in the tests by contrast to the control corroborated the phytotoxicity of TDP was the concentration-response effect. The adverse effect on Lens culinaris growth showed an inverse correlation with ECs. The two parameters of GP and RL supported to calculate the two toxicity indices, namely the SGI and the REI. The phytotoxic risk assessment revealed that $0.1 \%$ of TDP caused a slight phytotoxicity according to the SGI, while it posed high phytotoxicity whilst taking the REI into account. It was found that $0.5 \%$ of TDP could exert a lethal effect (extreme phytotoxicity) on the RE. This demonstrates that the REI is more restricted and sensitive phytotoxicity index than the SGI. Hence, it is pretty potential to fulfil qualitative/semiqualitative toxicity assessment using RLI in the prospective future. This reconfirms that RLI have more practical significance for toxic assessment, compared with SGI. Conclusively, a simple but sensitive, effective and economical protocol of bioassay was designed for the proper assessment of phytotoxic risks and potentials. The new results are in accord with the previous data on phytotoxicity of surfactant-containing detergents and chemical mixtures to plant seedlings [11, 23, 24, 27-33].

\section{Acknowledgements}

Authors are grateful to acknowledge the study was funded by Shenzhen Municipal Government and Shenzhen MSU-BIT University. To complete the article, the efforts of Dr. Annah Pasipanodya, Dr. Niaz Ali and Dr. Kristian Hvidtfeldt to correct and improve the English texts is appreciated. In particular, Dr. K. Hvidtfeldt did not merely help the textual improvement in English but also share the constructive comments on some scientific issues, which is also acknowledged here.

\section{Conflict of Interest}

The authors have no financial interest nor any conflict of interest in regard to the article.

\section{Bibliography}

1. Ojo O A and Oso B A. "Biodegradation of synthetic detergents in wastewater". African Journal of Biotechnology 8.6 (2009): 1090-1109.

2. Shu W C and Ding W H. "Determination of fluorescent whitening agents in laundry detergents and surface waters by solidphase extraction and ion-pair high-performance liquid chromatography". Journal of Chromatography A 1088.1-2 (2005): 218-223.

3. Ferradj A and Idouhar M. "Determination of anionic surfactants in wastewater treatment plant in Algiers City". Desalination and Water Treatment 57.53 (2016): 25677-25685.

4. Chen Y., et al. "Microbial community assembly in detergent wastewater treatment bioreactors: Influent rather than inoculum source plays a more important role". Bioresource Technology 287 (2019): 121467.

5. Aboulhassan MA., et al. "Removal of surfactant from industrial wastewaters by coagulation flocculation process". International Journal of Environmental Science and Technology 3.4 (2006): 327-332.

6. Warne MSJ and Schifko AD. "Toxicity of laundry detergent components to a freshwater cladoceran and their contribution to detergent toxicity". Ecotoxicology and Environmental Safety 44. (1999): 196-206.

7. Kogawa AC., et al. "Synthetic detergents: 100 years of history". Saudi Pharmaceutical Journal 25.6 (2017): 934-938.

8. Liu W., et al. "Quantitative structure-activity relationship between the toxicity of amine surfactant and its molecular structure". Science of the Total Environment 702. (2020): 134593.

9. Gassama UM., et al. "Influence of municipal wastewater on rice seed germination, seedling performance, nutrient uptake, and chlorophyll content". Journal of Crop Science and Biotechnology 18.1 (2015): 9-19.

10. Ostroumov S A and Solomonova E A. "Phytotoxicity of a surfactant-containing product towards macrophytes". Russian Journal of General Chemistry 83.13 (2014): 2614-2617.

11. Ostroumov S A. Biological effects of surfactants on organisms, MAKS-Press, Moscow (2001).

12. Solomonova E A and Ostroumov S A. "Tolerance of an aquatic macrophyte Potamogeton crispus L. to sodium dodecyl 
sulphate". Moscow University Biological Sciences Bulletin 62.4 (2007): 176-179.

13. Song J., et al. "A phenotypic and genotypic evaluation of developmental toxicity of polyhexamethylene guanidine phosphate using zebrafish embryo/larvae". Toxics 8.2 (2020): 33-47.

14. Scott $\mathrm{M} \mathrm{J}$ and Jones $\mathrm{M} \mathrm{N}$. "The biodegradation of surfactants in the environment". Biochimica et Biophysica Acta (BBA) - Biomembranes 1508.1-2 (2000): 235-251.

15. Metcalfe C D., et al. "Carcinogenicity and mutagenicity testing of extracts from bleached kraft mill effluent". Chemosphere 30.6 (1995): 1085-1095.

16. Wieck S., et al. "Fragrance allergens in household detergents". Regulatory Toxicology and Pharmacology 97 (2018): 163-169.

17. Wang M., et al. "Laundry detergents and detergent residue after rinsing directly disrupt tight junction barrier integrity in human bronchial epithelial cells". The Journal of Allergy and Clinical Immunology 143.5 (2019): 1892-1903.

18. Mtisi M and Gwenzi W. "Evaluation of the phytotoxicity of coal ash on lettuce (Lactuca sativa L.) germination, growth and metal uptake". Ecotoxicology and Environmental Safety 170.15 (2019): 750-762.

19. Bagur-González M G., et al. "Toxicity assessment using Lactuca sativa L. bioassay of the metal (loid)s $\mathrm{As}, \mathrm{Cu}, \mathrm{Mn}, \mathrm{Pb}$ and $\mathrm{Zn}$ in soluble-in-water saturated soil extracts from an abandoned mining site". Journal of Soils and Sediments 11.2 (2010): 281289.

20. EPA U S., Ecological effects test guidelines (OPPTS 850.4200): seed germination/root elongation toxicity test (1996).

21. Ostroumov S A., et al. "Toxicity of gold nanoparticles for plants in experimental aquatic system". Moscow University Biological Sciences Bulletin 69.3 (2014): 108-112.

22. Lazareva EV and Ostroumov SA. "Accelerated decrease in surfactant concentration in the water of a microcosm in the presence of plants: Innovations for phytotechnology". Doklady Biological Sciences 425.1 (2009): 180-182.

23. Ostroumov SA. "Toxicity testing of chemicals without use of animals". Russian Journal of General Chemistry 86.13 (2017): 2933-2941.

24. Cai X and Ostroumov SA. "Phytotests for assessing phytotoxicity of "Blue moon" liquid detergent: Lens culinaris seeds". Issues in Biological Sciences and Pharmaceutical Research 9.3 (2021): 93-100.

25. Mtibaa R., et al. "Biodegradation and toxicity reduction of nonylphenol, 4-tert-octylphenol and 2,4-dichlorophenol by the ascomycetous fungus Thielavia sp HJ22: Identification of fungal metabolites and proposal of a putative pathway". Science of the Total Environment 708.15 (2020): 135129.

26. Bozym M. "Assessment of phytotoxicity of leachates from landfilled waste and dust from foundry". Ecotoxicology 29.4 (2020): 429-443.

27. Ostroumov S A and Maximov V N. "Bioassay of surfactants based on the disruption of seedling attachment to the substrate and rhizoderm root hair formation". Biology Bulletin 18.4 (1991): 383-386.

28. Ostroumov S A and Khoroshilov V S. "Biological-activity of waters polluted with a liquid surfactant-containing detergent". Izvestiya Akademii Nauk SSSR Seriya Biologicheskaya 3 (1992): 452-458.

29. Ostroumov S A. Biological effects of surfactants. CRC Press, Taylor \& Francis, Boca Raton, London, New York (2006).

30. Ostroumov S A and Solomonova E A. "Synthetic detergent "Aist-Universal": effects on seed germination and seedling elongation of buckwheat Fagopyrum esculentum". Toxicological Review 5 (2007): 42-43.

31. Poklonov V A, Kotelevtsev S V, Ostroumov S A. "About the effects of detergents on Vigna radiata and Lens culinaris under a biotest". Toxicological Review 5 (2012): 49-52.

32. Ostroumov S and Kotelevtsev S. "Assessing environmental hazards of chemicals: the efficient method with higher plants". Black Sea Scientific Journal of Academic Research 26.8 (2015): 8-11.

33. Cai X and Ostroumov S A. "Finding of toxicity of herbal shampoo to plant seedlings: phytotest of mixture product that contains membranotropic chemicals as components" Ecologica 28.101 (2021): 6-10.

\section{Assets from publication with us}

- Prompt Acknowledgement after receiving the article

- Thorough Double blinded peer review

- Rapid Publication

- Issue of Publication Certificate

- High visibility of your Published work

Website: www.actascientific.com/

Submit Article: www.actascientific.com/submission.php Email us: editor@actascientific.com

Contact us: +919182824667 